\title{
Correction to: Iterative principal component analysis method for improvised classification of breast cancer disease using blood sample analysis
}

\author{
Geetharamani $\mathbf{R}^{1} \cdot$ Sivagami $\mathbf{G}^{1}$
}

Published online: 23 August 2021

(c) International Federation for Medical and Biological Engineering 2021

\section{Correction to: Medical \& Biological Engineering \&}

\section{Computing}

https://doi.org/10.1007/s11517-021-02405-y

In the original publication of the article, Algorithm1 titled "Iterative Principal Component Analysis method for Breast Cancer Prediction" was missed and Figure 1 was duplicated. The Algorithm1 was inserted prior to Algorithm 2. The duplicate figure was removed.

The original article has been corrected.

Publisher's note Springer Nature remains neutral with regard to jurisdictional claims in published maps and institutional affiliations.

The original article can be found online at https://doi.org/10.1007/ s11517-021-02405-y

Sivagami G

shiv.haida@gmail.com

1 Department of Information Science and Technology, College of Engineering, Anna University, Guindy, Chennai 600025, India 